\title{
Two years on, major drug safety reforms stalled
}

\author{
- Cite as: CMAJ 2017 January 23;189:E129-30. doi: 10.1503/cmaj.109-5372
}

W hen Terence Young's daughter Vanessa died from an adverse effect of medication in March 2000 , he swore he would find out why and make sure that others wouldn't suffer the same tragedy.

Young seemed close to achieving his goal in 2014, when the federal government passed the Protecting Canadians from Unsafe Drugs Act, also named Vanessa's Law in memory of his daughter. The law gives the federal health minister new powers to monitor, recall and share information about drugs and other health products to improve their safety. But two years later, Health Canada still isn't enforcing these reforms in letter or spirit, says Young.

"The latest information I have is that it will begin to be enforced in the first quarter of next year," he said at a recent symposium on corruption in health care hosted by the Munk School of Global Affairs at the University of Toronto.

Young estimated that 10000 Canadians die each year from taking medications exactly as prescribed, and about $70 \%$ of these deaths are preventable. "Every delay means more people are dying unnecessarily."

Some aspects of Vanessa's Law came into force when the bill received royal assent in November 2014. These include the health minister's new powers to order recalls and label changes, as well as tougher penalties for selling unsafe drugs and health products. Manufacturers now face jail time and fines up to $\$ 5$ million per day.

But other key reforms are stalled until Health Canada writes supporting regulations. Provisions in this limbo include the health minister's ability to order tests and reassessments, as well as measures to strengthen monitoring of products already on the market.
Under Vanessa's Law, manufacturers must report warnings or recalls issued for their products in other countries, and health institutions must report all serious drug reactions and medical device incidents. So long as these reforms are on hold, harmful products will stay on the market far too long, says Young. A 2015 CMAJ commentary argued that the success of Vanessa's Law would hinge on how the government implements mandatory adverse event reporting. It's estimated that less than $5 \%$ of drug reactions are documented and fewer still are reported to the Canadian Institute for Health Information.

Health Canada spokesperson Maryse Durette says regulations will be developed in phases, with the first phase planned for publication in the coming months.

But Young argues that the process has already dragged beyond what he would expect as a former member of parliament, even allowing for months of consultation and the upheaval of a federal election. "It's been over a year since the current government won a majority and they could have begun enforcing, for example, reporting of serious drug reactions," he says. "I'm extremely frustrated it's taken so long."

\section{Transparency muddied}

Speed of enforcement isn't the only concern for proponents of Vanessa's Law. In March 2016, Health Canada issued a draft guidance document that clinicians, researchers and legal experts say undermines the law's transparency provisions.

Health Canada closely guards the safety and effectiveness data it obtains from companies during the development, licensing and marketing of health products as "confidential business data." This secrecy has been a safety risk in the past, such as, for example, when doctors were

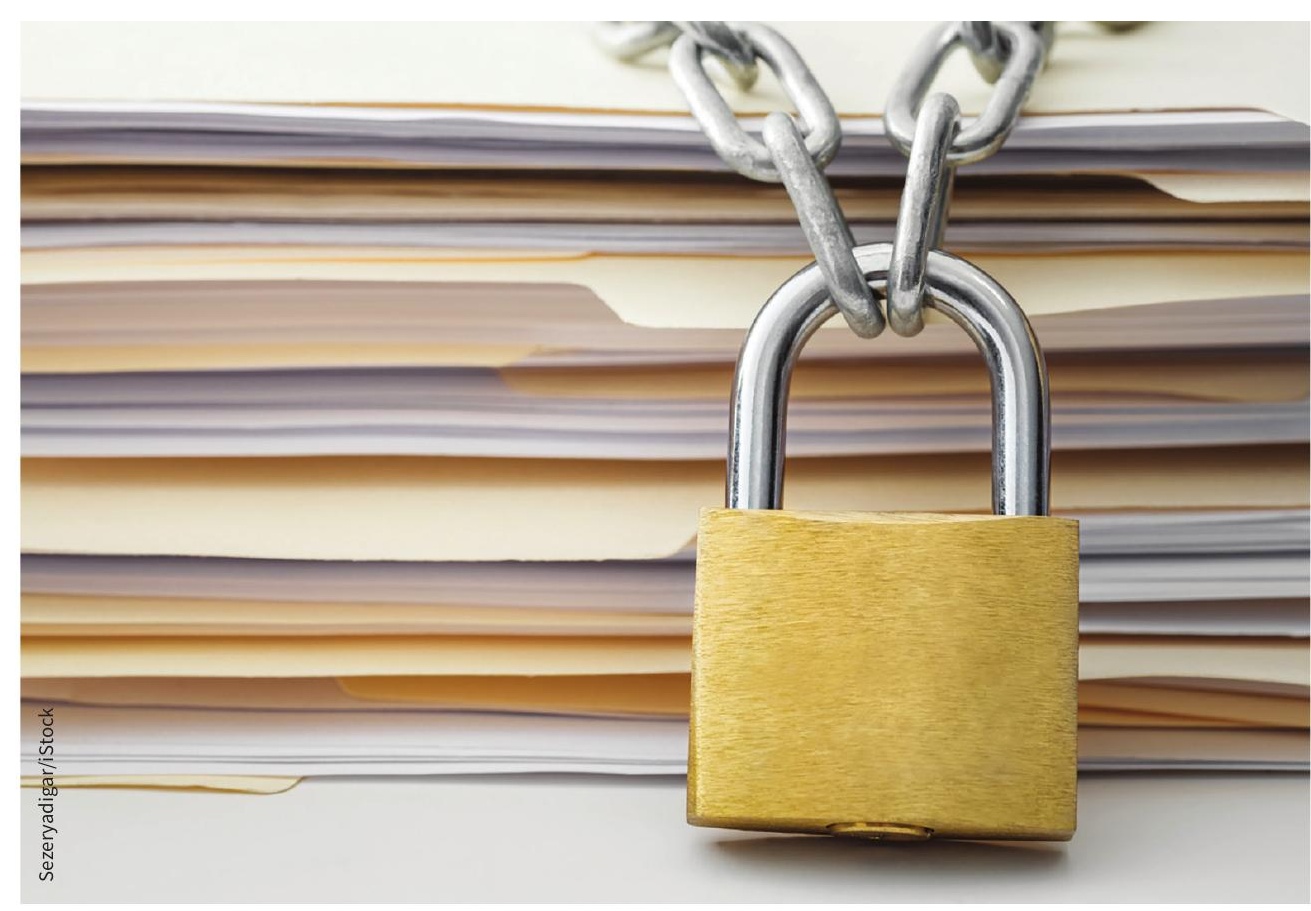

Health Canada is still restricting access to drug safety data under Vanessa's Law, according to the former Member of Parliament who introduced the bill. 
widely prescribing selective serotonin reuptake inhibitors to teenagers, and Health Canada didn't disclose evidence it held of harms to that age group.

Vanessa's Law aims to increase transparency by allowing the federal health minister to share confidential information to protect or promote health or public safety. But Health Canada's draft guidance imposes a complicated vetting process that experts say will bar most physicians and researchers.

Before a person may request information from Health Canada, they must first exhaust "all other possible sources." Negotiating with drug companies for data may add months or years of delay, according to a May 2016 letter signed by 60 international clinicians and researchers, including the editor-in-chief of BMJ.

Beyond this hurdle, Health Canada also requires a "formal plan" for use of the information, potentially excluding physicians who want to check original data to guide prescribing. In addition, the government department demands that those making the request present proof of a "record of contribution to improving the health and/or safety of Canadians," which might preclude early-career researchers and clinicians from applying. And finally, a confidentiality agreement must be signed, which may bar clinicians and researchers from discussing or publishing their findings, as many scientific journals require access to the raw data supporting submissions.

The expert letter calls these requirements a "recipe for ensuring minimal use of the drug data Health Canada holds." Another letter in May 2016 signed by legal scholars argues the guidance goes against the purpose of Vanessa's Law and potentially violates the Charter of Rights and Freedoms.

Durette says Health Canada "recognizes that stakeholders have concerns. That's why we have held consultations with stakeholders to better understand their needs for information and how it will be shared."

"Health Canada has already disclosed more than 36200 pages of unpublished clinical study reports in response to requests under this authority," she adds. However, the experience of at least one physician who requested information under the new law confirms experts' worst fears. Dr. Nav Persaud (a CMAJ associate editor) fought for years to access data on the morning sickness drug Diclectin. Last year, Health Canada disclosed 35000 pages to the physician (accounting for nearly all of the information the regulator says it has shared under Vanessa's Law). After reviewing the information, Persaud told the Toronto Star the drug "might not be effective at all," but because of the confidentiality agreement he signed, he is unable to provide evidence for his concern.

Young says the limits Health Canada has set on transparency under Vanessa's Law are "outrageous" and "should be trashed." He's writing an open letter to Prime Minister Justin Trudeau and said he will consider suing the government if Health Canada doesn't enforce the law in coming months.

"I'm afraid they're never going to be transparent," Young says. "Then we're right back where we started when Vanessa died."

Lauren Vogel, CMAJ 